\title{
GHG AND AEROSOL EMISSION FROM FIRE PIXEL DURING CROP RESIDUE BURNING UNDER RICE AND WHEAT CROPPING SYSTEMS IN NORTH-WEST INDIA
}

\author{
Prasenjit Acharya ${ }^{a^{*},}$ S.Sreekesh ${ }^{a}$, Umesh Kulshrestha ${ }^{b}$ \\ ${ }^{a}$ CSRD, School of Social Science, Jawaharlal Nehru University, 110067 New Delhi, India - prasenjit.ac@gmail.com \\ ${ }^{a}$ CSRD, School of Social Science, Jawaharlal Nehru University, 110067 New Delhi, India - ssreekesh@ gmail.com \\ ${ }^{\mathrm{b}}$ School of Environmental Science, Jawaharlal Nehru University, 110067 New Delhi, India - umeshkulshrestha@gmail.com
}

Commission II, WG II/ 1 - Spatio-temporal Modelling

KEY WORDS: Modelling, GHG emission, EVI, Fourier transformation, MODIS

\begin{abstract}
:
Emission of smoke and aerosol from open field burning of crop residue is a long-standing subject matter of atmospheric pollution. In this study, we proposed a new approach of estimating fuel load in the fire pixels and corresponding emissions of selected GHGs and aerosols i.e. $\mathrm{CO}_{2}, \mathrm{CO}, \mathrm{NO}_{2}, \mathrm{SO}_{2}$, and total particulate matter (TPM) due to burning of crop residue under rice and wheat cropping systems in Punjab in north-west India from 2002 to 2012. In contrasts to the conventional method that uses RPR ratio to estimate the biomass, fuel load in the fire pixels was estimated as a function of enhanced vegetation index (EVI). MODIS fire products were used to detect the fire pixels during harvesting seasons of rice and wheat. Based on the field measurements, fuel load in the fire pixels were modelled as a function of average EVI using second order polynomial regression. Average EVI for rice and wheat crops that were extracted through Fourier transformation were computed from MODIS time series 16 day EVI composites. About $23 \%$ of net shown area (NSA) during rice and $11 \%$ during wheat harvesting seasons are affected by field burning. The computed average fuel loads are $11.32 \mathrm{t} / \mathrm{ha}( \pm 17.4)$ during rice and $10.89 \mathrm{t} / \mathrm{ha}( \pm 8.7)$ during wheat harvesting seasons. Calculated average total emissions of $\mathrm{CO}_{2}, \mathrm{CO}, \mathrm{NO}_{2}, \mathrm{SO}_{2}$ and TPM were 8108.41, 657.85, 8.10, 4.10, and $133.21 \mathrm{Gg}$ during rice straw burning and 6896.85, 625.09, $1.42,1.77$, and $57.55 \mathrm{Gg}$ during wheat burning. Comparison of estimated values shows better agreement with the previous concurrent estimations. The method, however, shows its efficiency parallel to the conventional method of estimation of fuel load and related pollutant emissions.
\end{abstract}

\section{INTRODUCTION}

Emission from vegetation fire is one of the major sources of atmospheric pollution (Yang et al., 2008). Enormous amount of trace gases and aerosols are injected into the atmosphere affecting regional to global climate (Hodzic et al., 2007). Large scale emission from vegetation fire and its long range transportation (Badarinath et al., 2009) is one of the leading factors which modify the regional as well as global weather pattern through altering the radiation balance responsible for global climate change (Hobbs et al., 1997). The global emission of pyrogenic species from wide variety of biomass fuel was presented by Andreae and Merlet (2001). It shows that among all the biomass fuel types, forest fire is the major source of $\mathrm{CO}_{2}$ emission, agricultural residue burning comes in the second and contributes nearly contribute $25 \%$ of the total biomass burned (Chang and Song, 2009).

As an agrarian country, India produces million tonnes of unutilized crop residue that are usually burned in the open field during harvesting season. The quantity of crop waste produced is closely associated with levels of farm mechanisation. Use of combined harvester produces an enormous amount of crop waste majority of which is cleared through the on-farm burning process. Previous estimates of total crop residue burnt over India shown that about $116 \mathrm{Mt}$ of crop waste was burnt in open field burning process (Venkataraman et al., 2006). Approximately $17-35 \%$ of crop waste comes from cereal crops where rice-wheat system contributes more than $60 \%$ of it.
Estimates reported by Gupta et al., (2004) showed that about 17-19 million tonnes of dry rice and wheat residue are disposed through field burning. According to their estimate for the year 2000, emissions of $\mathrm{CH}_{4}, \mathrm{CO}, \mathrm{N}_{2} \mathrm{O}$ and $\mathrm{NO}_{\mathrm{x}}$ from rice and wheat residue burning in India were 110, 2306, 2, and $84 \mathrm{Gg}$ respectively. In a similar study, emissions of $\mathrm{CH}_{4}, \mathrm{CO}, \mathrm{N}_{2} \mathrm{O}$, and $\mathrm{CO}_{2}$ for the same year (2000) were estimated as $68 \pm 51$, $541 \pm 387,14 \pm 9$, and $34435 \pm 682 \mathrm{Gg}$ respectively from open field burning of wheat residue (Sahai et al., 2007). All these studies, mentioned above, reported the emission of pollutant from biomass burning by using conventional approach (Langmann et al., 2009) which requires average fuel load, total burned area, the combustion completeness and the emission factors of the respective pollutants. Estimation of fuel load, in this connection, utilizes the residue to product ratio (RPR) that computes the total fuel load as a function of production (Jain et al., 2014). Though the approach holds a comprehensive view of the total emission, but fails to capture the spatial variation of emission. In this study we adopt a new approach to model the fuel load as a function of enhanced vegetation index (EVI) in the fire pixel and thereby, compute the emission of GHGs and aerosol (TPM). Since, EVI is related to the total biomass content, varying levels of EVI leads to variation in fuel load in the fire pixels and thereby, produce differences in emission.

\footnotetext{
Corresponding author
} 


\section{MATERIALS AND METHOD}

\subsection{Study area}

As part of north-west India, Punjab plain (Figure 1), where more than $75 \%$ of cropped area is under combine harvesting (Gupta et al., 2003), produces a considerable amount of crop residue in each year. The estimate shows that almost $70-80 \%$ of the rice-wheat system in Punjab is machine harvested and that produces an enormous amount of residue left behind unused in the field. The burning of these residues produces trace gases and aerosols from mid-October to mid-November during harvesting season of rice and from end of April to end of May during harvesting season of wheat. Majority of the area under crop in Punjab is dominated by the double cropping system. However, triple cropping system is also practiced simultaneously. The estimated average farm size is 3.77 hectares (MoA, 2012). Large farm size enabled the farmers to mechanize the farming activity. Farmers opted burning these crop residues because (a) residue impedes the tillage operation, (b) the gap between kharif and rabi crop is very short, not enough to biologically decompose the residue and (c) it is the easiest and fastest way to clear the field and prepare it for the next crop.

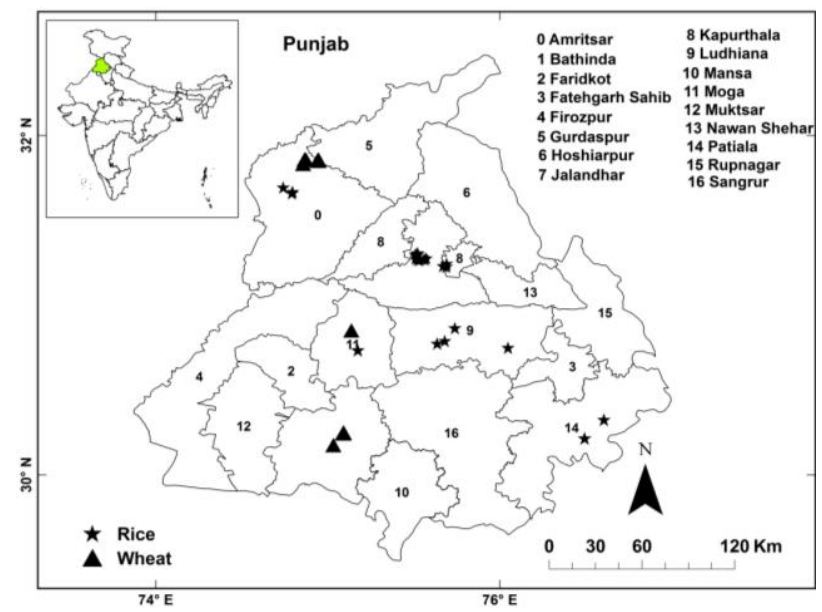

Figure 1. Field locations of fuel load measurement during rice and wheat harvesting season in Punjab plain (North-West India).

\subsection{Data}

2.2.1 Enhanced Vegetation Index (EVI): MODIS level 3 16 day composite (MOD13Q1) enhanced vegetation index (EVI) with pixel dimension $250 \mathrm{~m}$ was used in this work. EVI was successfully used to find the correlation with leaf area index (LAI) and is recommended for its higher sensitivity in high biomass region (Huete et al., 2002). Because of its linearity in correlation while measured against biomass in paddy field, it is highly recommended to study the fuel load in cropland (Sakamoto et al., 2005). EVI for Julian Day (JD) 129 of a year to JD 113 of the following year was used for the period 2002-12. It includes twenty growing seasons (i.e. ten for kharif and ten for rabi). For our convenience, we have selected the time series progression of EVI from JD 129 to 321 for rice and JD 337 to 113 for wheat for their respective cropping cycle.
2.2.2 MODIS Fire Product: MODIS level $3 \quad 8$ day composite (Giglio et al., 2006) fire products from Terra (MOD14A2 ) and Aqua (MYD14A2) platforms were used to extract burned area over Punjab during rice and wheat harvesting seasons. Fire products were used from JD 281 to 329 during rice harvesting season and JD 113 to 177 during wheat harvesting seasons for the 2002-12 period. Nominal and high confidence fire pixels (pixel value 8,9 ) assured by the quality confidence flags were used to extract the burned area.

2.2.3 Crop area statistics: Area statistics related to net shown area and the area under major crops for the year 2011-12 over Punjab were obtained from Directorate of Economics and Statistics (DES) under Ministry of Agriculture, Government of India, in order to compare it with estimated area under dominant crops.

\subsection{Crop Mapping}

2.3.1 Temporal smoothing of EVI using Savitzky-Golay filter: Since our focus is to model the fuel load and its associated pollutant emission from fire pixels under rice and wheat systems, as a prerequisite to this, it is necessary to classify all the crop pixels according to cropping pattern. To accomplish it, we extracted the crop pixels for the year 2011-12 by running decision tree (DT) classification method based on the band threshold rules of descriptive statistics and factor analysis (Sun et al., 2011). The baseline assumption of doing DT classification during 2011-12 is that- these crop pixels have not undergone any non-agrarian transformation throughout the study period (2002-12). The extracted crop pixels were then used for masking of 16 day EVI composites for the year 201112 and were then stacked together to produce a hypercube of 23 layers from JD 129 of 2011 to JD 113 of 2012. The spectral profile of each pixel in that hypercube is just the time signal of EVI recorded over all 23 layers (Figure 2a). Even though the available EVI data were corrected for the effect of aerosol, the presence of thick cloud in a pixel over the composite period of 16 days makes it difficult to reconstruct the surface reflection (Sakamoto et al., 2005). We, therefore, used Savitzky-Golay temporal smoothing filter to get smoothed curve (Figure $2 \mathrm{~b}$ ) by reducing the random effect (Chen et al., 2004).
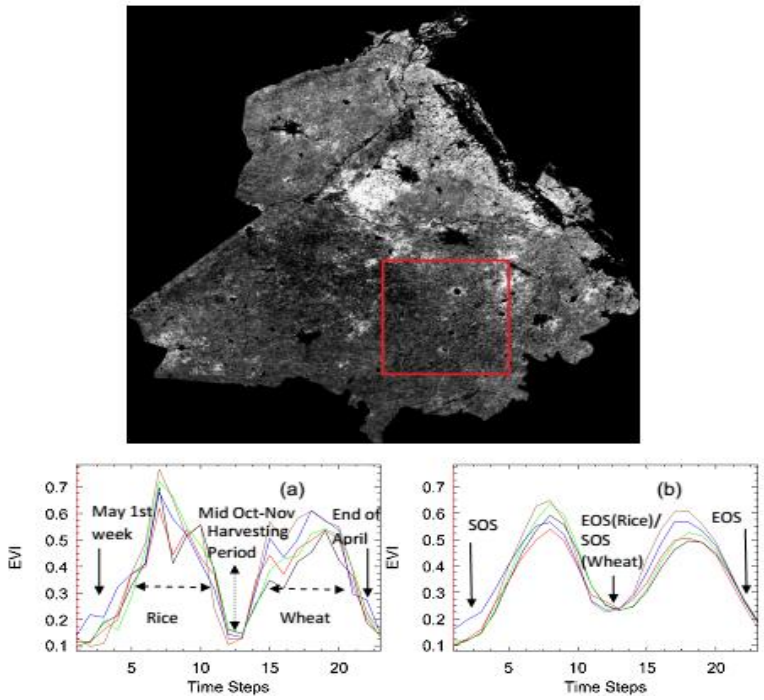

Figure 2. Time series EVI profile (spectra) of selected locations in the red bounding box. The lower left panel (a) shows the 
original EVI profile of MODIS VI product and lower right panel (b) shows the smoothed profile of the same locations after running Savitzky-Golay filter. SOS and EOS in the lower right graph indicate the start of season and end of season respectively.

2.3.2 Fourier analysis: The strength of the signal processing of Fourier analysis was harnessed by several authors to analyze the land surface phenology using only the amplitude and phase term of the most important periodic component (Azzali and Menenti, 2000). The amplitude and phase term, assigning the maximum value of EVI in a particular crop cycle and the time when this maximum has occurred can easily be computed through discrete Fast Fourier Transformation (FFT). The Fourier transform of this discrete series is expressed as (Eq 1),

$$
y(t)=a_{0}+\sum_{k=1}^{m}\left(A_{k} \cos \frac{2 \pi k t}{N}+B_{k} \sin \frac{2 \pi k t}{N}\right)
$$

where $y(t)$ is the fitted signal, $a_{0}$ represents the mean of whole time series, ${ }^{k}$ is integer frequency or order of the harmonic term, $A_{k}$ and $B_{k}$ are the Fourier coefficients of real and imaginary part. We used Fourier transform subroutines embedded in ENVI 5.1 implemented by Interactive Data Language (IDL, Research System Inc, Boulder, USA). The phase and amplitude term of the $2^{\text {nd }}$ and $3^{\text {rd }}$ order harmonic term of the time series EVI, representative of crop type, were derived from Fourier analysis and stacked together followed by unsupervised clustering to merge the initial 50 classes into 6 different cropping systems.

\subsection{Fuel Load Modelling}

To estimate the fuel load per MODIS pixel, we carried out the weighting of residue load in the plot size of 1 square meter in sample field locations as shown in the Figure 1 during the harvesting seasons in 2011-12. On an average, 8 plots per sample field were selected. The average fuel load $\left(\mathrm{Kg} \mathrm{m}^{-2}\right)$ of all these plots was computed per sample fields and translated into Tonnes per hectare unit ( $t / h a)$. The measured fuel load ranges between 6.92-18.43 t/ha with an average of $10.9 \mathrm{t} / \mathrm{ha}$ for rice straw and between 3.2-6.4 t/ha with an average of $4.5 \mathrm{t} / \mathrm{ha}$ for wheat straw. Fuel load per MODIS pixel was then computed by simply multiplying the pixel dimensions with the estimated average fuel loads ( $t / h a)$. Average EVI of the pixels corresponding to the sample fields in the period of sowing through physiological maturity to harvesting season was computed from time series EVI image and these time averaged EVI values was used to model the fuel load in MODIS fire pixels. It is important to mention at this point that, we assume higher average EVI over a cropping cycle leads to high leaf area index, in other words, high biomass content. And thereby, the production of residue that leftover in the field for burning also remains high. Therefore, we used the average EVI, computed from each time step EVI values over a cropping cycle, as independent variable and measured fuel load of the pixel at the sampling location as dependent variable. Total 21 post harvested rice field samples and 19 wheat field samples were obtained and these are separately plotted with their respective averaged EVI (Figure 3).

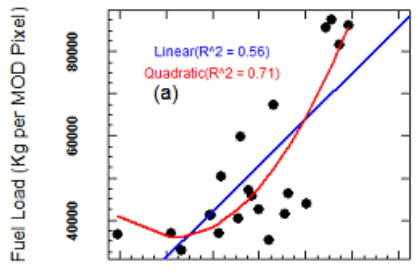

$\begin{array}{lllllll}0.26 & 0.28 & 0.30 & 0.32 & 0.34 & 0.36 & 0.38\end{array}$

Avg EVI

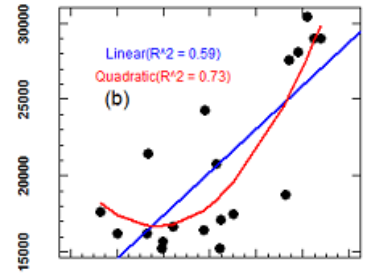

$\begin{array}{lllllll}0.26 & 0.28 & 0.30 & 0.32 & 0.34 & 0.36 & 0.38\end{array}$

Avg EVI
Figure 3. Scatter plot of fuel load and EVI of sample locations for (a) rice and (b) wheat per MODIS pixel.

Both the linear and polynomial 2nd order regression functions following ordinary least square (OLS) method have been tested over two sets of data series. The detail of the model parameters are given in Table 1. It is observed that both the models appeared as significant but they differ from each other in terms of their explanatory power.

\begin{tabular}{|c|c|c|c|c|c|}
\hline & & Coefficients & Estimate & $\operatorname{Pr}(>|t|)$ & $\mathrm{R}^{2}$ \\
\hline \multirow[t]{5}{*}{ Rice } & \multirow[t]{2}{*}{ Linear } & $\begin{array}{l}\text { Intercept } \\
\left(\beta_{0}\right)\end{array}$ & -121441 & $\begin{array}{l}0.0026 \\
7 * *\end{array}$ & \multirow[t]{2}{*}{0.56} \\
\hline & & $\begin{array}{l}\text { AVG_EVI } \\
\left(\beta_{1}\right)\end{array}$ & 545194 & $\begin{array}{l}9.09 \mathrm{e}- \\
05 * * *\end{array}$ & \\
\hline & \multirow{3}{*}{$\begin{array}{l}\text { Polyno } \\
\text { mial 2nd } \\
\text { Order }\end{array}$} & $\begin{array}{l}\text { Intercept } \\
\left(\beta_{0}\right)\end{array}$ & 745944 & $\begin{array}{l}0.0187 \\
8 *\end{array}$ & \multirow[t]{3}{*}{0.71} \\
\hline & & $\begin{array}{l}\text { AVG_EVI } \\
\left(\beta_{1}\right)\end{array}$ & -5012900 & $\begin{array}{l}0.0140 \\
7 *\end{array}$ & \\
\hline & & $\begin{array}{l}\text { AVG_EVI } \\
\left(\beta_{2}\right)\end{array}$ & 8847295 & $\begin{array}{l}0.0073 \\
8 * *\end{array}$ & \\
\hline \multirow[t]{5}{*}{ Wheat } & Linear & $\begin{array}{l}\text { Intercept } \\
\left(\beta_{0}\right)\end{array}$ & -25216 & $\begin{array}{l}0.0152 \\
54 *\end{array}$ & 0.59 \\
\hline & & $\begin{array}{l}\text { AVG_EVI } \\
\left(\beta_{1}\right)\end{array}$ & 142122 & $\begin{array}{l}0.0001 \\
27 * * *\end{array}$ & \\
\hline & \multirow[t]{3}{*}{$\begin{array}{l}\text { Polyno } \\
\text { mial 2nd } \\
\text { Order }\end{array}$} & $\begin{array}{l}\text { Intercept } \\
\left(\beta_{0}\right)\end{array}$ & 252084 & $\begin{array}{l}0.0190 \\
*\end{array}$ & \multirow[t]{3}{*}{0.73} \\
\hline & & $\begin{array}{l}\text { AVG_EVI } \\
\left(\beta_{1}\right)\end{array}$ & -1584430 & $\begin{array}{l}0.0178 \\
*\end{array}$ & \\
\hline & & $\begin{array}{l}\text { AVG_EVI } \\
\left(\beta_{2}\right)\end{array}$ & 2666023 & $\begin{array}{l}0.0109 \\
*\end{array}$ & \\
\hline
\end{tabular}

Table 1. Model parameters of Linear and Polynomial regression

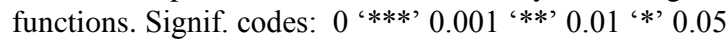

The model comparison through analysis of variance (ANOVA) test suggested that in both the cases polynomial regression model of order 2 works fairly good in accounting the data variance in average fuel load per MODIS pixel. Average EVI of rice was computed for each year during 2002-11 and that of wheat was computed for each year during 2003-12. The fire pixels, both from Terra and Aqua platform, were then used to extract the average EVI for each year in the respective time domain of rice and wheat harvesting. Model parameters of polynomial regression function were then applied to estimate the fuel load in the fire pixels. And these were further used to compute the emission of GHGs and aerosols.

\subsection{Emission of GHG and aerosol}

Emissions of GHGs and aerosol from fire pixel (Eq 2) were computed as product of fuel load in the burned pixel, the 
emission factor (EF) of a particular species and the combustion completeness or the combustion efficiency (CE) of the fuel (Seiler and Crutzen, 1980).

$$
\mathrm{E}_{i}=\mathrm{FL} * \mathrm{EF} * \mathrm{CE}
$$

Where $\mathrm{E}_{i}$ is the emission of particular trace gas species $i$. Crop specific emission factors of $\mathrm{CO}_{2}, \mathrm{CO}, \mathrm{NO}_{2}, \mathrm{SO}_{2}$ and TPM with CEs are given in the Table 2.

\begin{tabular}{lllcl}
\hline & \multicolumn{2}{c}{ Rice } & \multicolumn{2}{c}{ Wheat } \\
\hline Species & $\mathrm{EF}$ & $\mathrm{CE}$ & $\mathrm{EF}$ & $\mathrm{CE}$ \\
\hline $\mathrm{CO}_{2}$ & $791.3 \pm 12.5$ & $0.925 \pm 0.006$ & 1557.9 & 0.917 \\
& $\mathrm{a}$ & $\mathrm{a}$ & $\pm 85.8^{\mathrm{a}}$ & $\pm 0.005^{\mathrm{a}}$ \\
$\mathrm{CO}$ & $64.2 \pm 4.9^{\mathrm{a}}$ & & $141.2 \pm 14.8$ & \\
& & $\mathrm{a}$ & \\
$\mathrm{NO}_{2}$ & $0.79 \pm 0.05^{\mathrm{a}}$ & $0.32 \pm 0.06^{\mathrm{a}}$ & \\
$\mathrm{SO}_{2}$ & $0.4^{\mathrm{b}}$ & $0.4^{\mathrm{b}}$ & \\
$\mathrm{TPM}^{\mathrm{b}}$ & $13^{\mathrm{b}}$ & $13^{\mathrm{b}}$ & \\
\hline
\end{tabular}

Table 2. Emission factors $\left(\mathrm{g} \mathrm{kg}^{-1}\right)$ and combustion efficiency (CE) from burning of rice and wheat straw. ${ }^{\mathrm{a}}$ After Zhang et al., 2008, ${ }^{\mathrm{b}}$ After Andreae \& Merlet, 2001

\subsection{Sources of Uncertainty}

The uncertainty estimation of the modelled output needs corresponding field measurements. However, the redundancy of these actual measurements often leads the model outcome to be untested in terms of its uncertainty level. In such cases, dealing the uncertainty of the input parameters is a viable solution to this particular issue. We, therefore, describe the potential sources of uncertainty regarding EVI and measured fuel load in the field as the input parameters of the developed polynomial regression model. The sources of uncertainty of EVI are well documented (Huete \& Justice, 1999) and can be related to removal of cloud and atmospheric effect from surface reflectance. The propagation of uncertainties of the fuel load measurement in the field, on the other hand, related to the sample size of $1 \mathrm{~m}^{2}$ plots per target crop field, the spreading (distribution) of crop residue in the field, as well as the time lag between the harvesting of the crop and weighing of the crop residue in the field. In addition to that, the accuracy of the classification of cropping system that arises from the size of the farmland, homogeneity and contiguousness of land cover type contribute to the uncertainty of the fuel load and associated level of emissions.

\section{RESULTS AND DISCUSSION}

\subsection{Cropped area estimation}

Figure 4 shows the classification of EVI pixels into different cropping systems. The estimated areas under these cropping systems, are given in Table 3, shows that; 29.4 lac hectare area is under rice crop, while, 38.4 lac hectare is under wheat crop in Punjab (Table 3). However, among other crops in Punjab, area under cotton shows 5.23 lac hectares, area under maize shows 1.24 lac hectare and area under potato shows 0.65 lac hectares.

The comparison of the estimated area with the reported area by DES shows that about $4.4 \%$ area is overestimated under rice cultivation, whereas, around $9 \%$ area is overestimated under wheat cultivation in Punjab. The computed proportion of area under rice cultivation to the net shown area (NSA) is $71 \%$, whereas, the actual proportion is $68 \%$. The computed proportion of area under wheat cultivation to NSA is 93\%, while, the reported proportion is $85 \%$. Nonetheless, the areas under Cotton, Maize and Potato remain in the limit of $\pm 7 \%$ deviation from the actual reported areas.

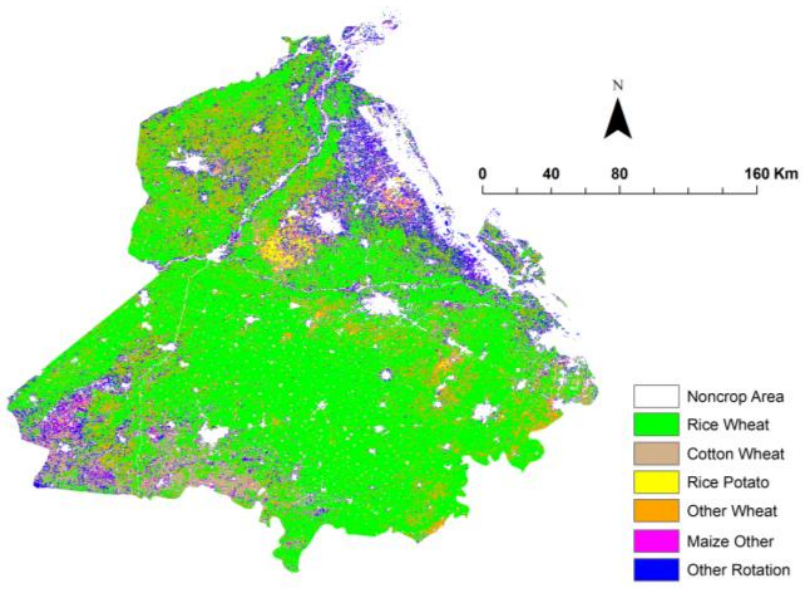

Figure 4. Dominant cropping patterns over Punjab.

\begin{tabular}{lrrr}
\hline Punjab & Estimated $^{\mathrm{a}}$ & Reported $^{\mathrm{b}}$ & \% Deviation \\
\hline Rice & 2941044 & 2815968 & 4.44 \\
Wheat & 3842420 & 3527317 & 8.93 \\
Cotton & 523060 & 515347 & 1.50 \\
Maize & 124084 & 128764 & -3.63 \\
Potato & 64981 & 69715 & -6.79 \\
\hline
\end{tabular}

Table 3. Comparison of major cropped area (in ha) between estimated, based on MODIS EVI (2011-12), and DES reported statistics. ${ }^{a}$ Estimated from MODIS EVI time series image (2011-12), ${ }^{\mathrm{b} D E S}$ reported statistics.

\subsection{Burned area}

Estimated area under fire event (FE) at the time of rice straw burning varies from 0.84 million hectare (Mha) in 2002 to 0.47 Mha in 2011 with a maximum of 1.24 Mha in 2005 and 2007. The temporal pattern of FEs, expressed in area unit, during this season shows an increasing trend in the period of 2002-09 (Figure 5). On the other hand estimated area under FEs at the time of wheat harvesting varies from 0.54 Mha in 2002 to 0.53 Mha in 2012 with substantial inter-annual variability.

The computed proportions of area under FEs to area under rice (ARC), wheat (AWC) and NSA show that about $28-42 \%$ of ARC was set on fire in Punjab during 2002-2010 with an exceptionally high fire count (42\%) in 2005 and 2007. The concurrent statistics on productivity during these particular years shows higher farm yield (MoA, 2005, 2007) that led to the higher production of biomass content. The estimation in 2011 accounts only $16 \%$ of ARC under fire that is surprisingly low in comparison to the estimations of previous years. If the atmospheric conditions remain invariable, then, such abrupt reduction of FEs in the period of rice straw burning can be due to the strong implication of environmental regulations by the state pollution control agency and increasing use of the crop 
waste in bio-energy production and other purposes. On the other hand, the estimated proportions of area during wheat straw burning are varying between $8-14 \%$ of AWC and $8-13 \%$ of NSA in the period of 2003-12. The notable difference in the total area under fire and its temporal pattern between rice and wheat is because of the fact that rice straws have high Silica content and are not suitable for animal feeding, while, because of the higher digestive fibre content, wheat straws are useful in this purpose. Therefore, rice straws are burnt more frequently than wheat.

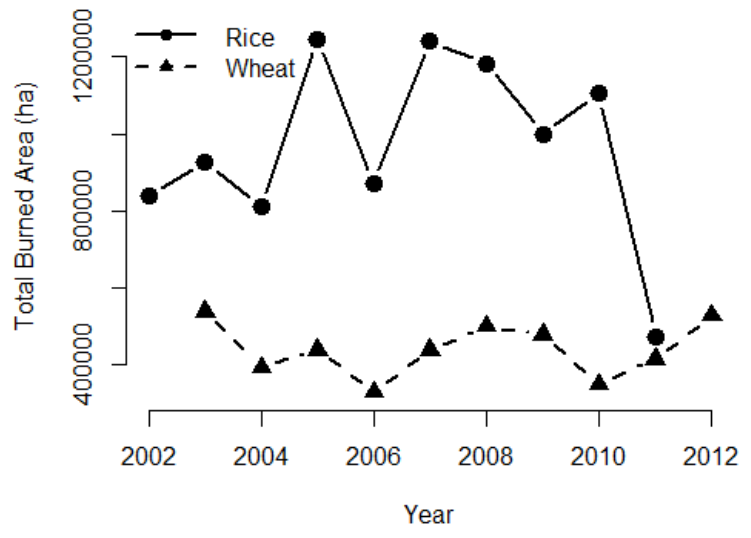

Figure 5. Total areas under fire during rice and wheat harvesting seasons in Punjab.

\subsection{Fuel load}

Estimated total fuel loads in the fire pixels vary from 7.61 Mt in 2002 to $5.60 \mathrm{Mt}$ in 2011 with an average of $11.08 \mathrm{Mt}$ during rice harvesting seasons in Punjab (Table 4). However, these estimations show a positive trend in the period of 2002-08 with fair inter-annual variability (Figure 6). Precisely, the reason for this increasing nature is- the augmented practices of on farm burning as well as increase in farm productivity during this period. The decreasing trend of total fuel load in post 2008 periods, perhaps, resulted from low farm yield of rice (MoA, 2009-2011).

\begin{tabular}{rrrr}
\hline \multicolumn{4}{c}{ Rice } \\
\hline Year & Total $(\mathrm{Mt})$ & Avg (t/ha) & SD $^{\mathrm{a}}$ \\
\hline 2002 & 7.61 & 9.09 & 17.2 \\
2003 & 11.04 & 11.92 & 18.8 \\
2004 & 8.57 & 10.55 & 13.5 \\
2005 & 13.28 & 10.66 & 21.1 \\
2006 & 9.81 & 11.28 & 16.3 \\
2007 & 18.69 & 15.07 & 20.3 \\
2008 & 13.60 & 11.51 & 20.0 \\
2009 & 9.68 & 9.68 & 15.1 \\
2010 & 12.90 & 11.68 & 21.0 \\
2011 & 5.60 & 11.81 & 10.7 \\
\hline Avg & 11.08 & 11.32 & 17.4 \\
\hline
\end{tabular}

Table 4. Yearly estimation of total fuel load ( in million tonnes or $\mathrm{Mt}$ ) and its average ( $\mathrm{t} / \mathrm{ha}$ ) during rice harvesting season.

Estimated total fuel loads, on the other hand, during wheat harvesting period vary from 4.56 Mt in 2003 to $4.67 \mathrm{Mt}$ in 2012 with almost no specific trend in the entire span of time (Table 5). The average total fuel load burned in the field during this season is $4.83 \mathrm{Mt}$ which is almost half of the average total fuel load produced during rice harvesting season.

\begin{tabular}{rrrr}
\hline \multicolumn{4}{c}{ Wheat } \\
\hline Year & Total (Mt) & Avg (t/ha) & SD $^{\mathrm{a}}$ \\
\hline 2003 & 4.56 & 8.46 & 8.2 \\
2004 & 3.76 & 9.57 & 8.6 \\
2005 & 6.75 & 15.37 & 10.9 \\
2006 & 2.76 & 8.36 & 7.4 \\
2007 & 7.09 & 16.18 & 11.7 \\
2008 & 5.80 & 11.61 & 9.6 \\
2009 & 4.85 & 10.12 & 7.9 \\
2010 & 2.45 & 7.00 & 6.0 \\
2011 & 5.58 & 13.43 & 10.3 \\
2012 & 4.67 & 8.84 & 6.6 \\
\hline Avg & 4.83 & 10.89 & 8.7 \\
\hline
\end{tabular}

Table 5. Yearly estimation of total fuel load (Mt) and its average ( $\mathrm{t} / \mathrm{ha}$ ) during wheat harvesting season.

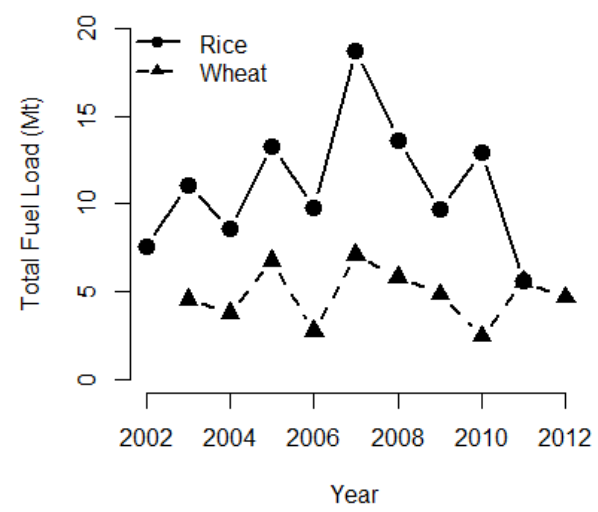

Figure 6. Total fuel loads during rice and wheat harvesting periods in Punjab.

This differences in average fuel load between rice and wheat are due to the high economic value of the wheat stubble that reduces the amount of the wheat residue left for open combustion. The inter-annual fluctuation in both rice and wheat residue is, therefore, the result of the net balance of the crop residue after the partial use of them in variety of purposes.

The average fuel load computed over the 2002-11 period from modelled values in burned pixel during rice harvesting seasons vary between $9-15 \mathrm{t} / \mathrm{ha}$ (Table 4 ) with a yearly average of 11.32 $\mathrm{t} / \mathrm{ha}( \pm 17.4)$. The same during wheat harvesting seasons (Table 5) calculated over the 2003-12 period ranges between 7-16 t/ha with a yearly mean of $10.9 \mathrm{t} / \mathrm{ha}( \pm 8.7)$. However, comparison of computed fuel load ( $t / h a)$ with other estimated values shows that, the estimate average fuel load for rice is fairly close to the reported estimation by Kushwaha and Singh, (2005) that ranges within 6.2-11.8 t/ha. However, the mean fuel load for wheat is not close enough to the reported level of 3.2-5.6 t/ha. This implies the need for further calibration of the model that was applied to compute the fuel load in wheat field. High standard deviation, generated from high variability of EVI, associated 
with mean fuel load in rice field explains the positively skewed distribution pattern of the modelled fuel load in fire pixels. Such a broad variation in EVI values occurred due to the onfarm practice of fine to coarse grain rice species and their management that widely varies in the north to south districts in Punjab plain. In contrast, standard deviation is less than mean fuel load during wheat straw burning explaining less variability in EVI values.

District wise fuel load distribution during rice harvesting season shows (Figure 7a) that; largely, the districts from central and south-eastern plains which include Mansa, Moga, Sangrur, Patiala, Fatehgarh Shahib, Ludhiana, Nawan Shehar and Rupnagar, are having high fuel load (11-13 t/ha). Moderate to low valued fuel load (9-10 and 8.6-9 t/ha), on the other hand, is observed mostly in the northern and western districts. The distribution during wheat harvesting season shows (Figure 7b) the occurrence of high fuel load in south-eastern, central and north-western plains of Punjab. However, moderate to low valued fuel loads are observed in the southern and few of the eastern districts. Earlier study by Sidhu et al. (1998) has shown that quantity of rice and wheat residue was highest in Sangrur, followed by Patiala, Amritsar and Ludhiana. These findings are also in compliance with the results of this study.

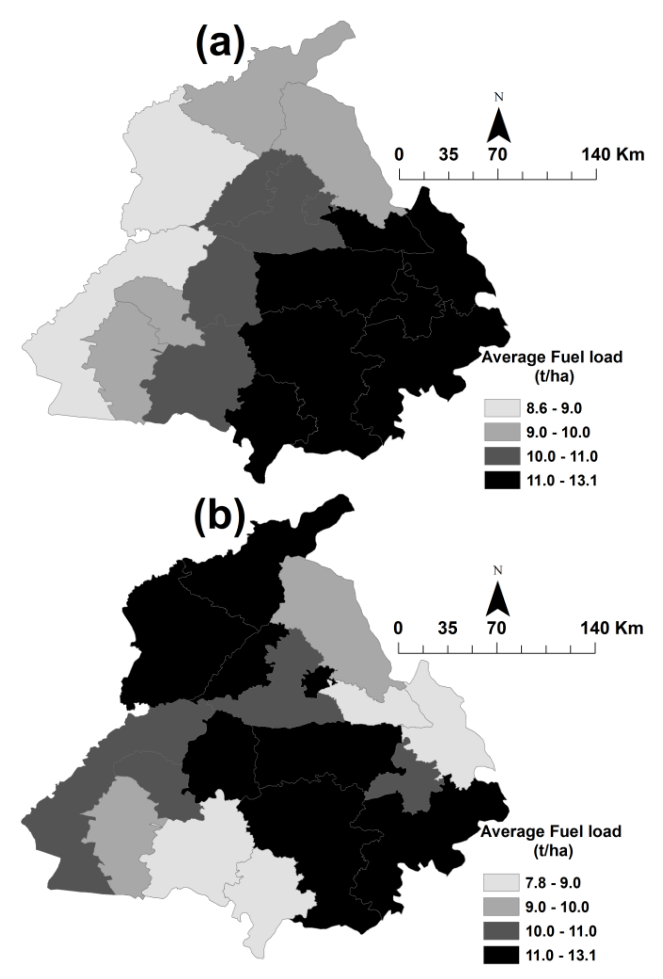

Figure 7. Spatial distribution of average fuel load (t/ha) during (a) rice and (b) wheat harvesting seasson.

\subsection{Emission scenario}

Estimated total GHGs and aerosol emissions during rice harvesting season show significant inter-annual variation from 2002-11 (Table 6). It shows an increasing trend over the period from 2002-08 during this season (Figure 8a-8e). Total estimated emissions during wheat harvesting seasons (Table 7), on the other hand, show considerable inter-annum variability with no specific trend. However, the estimated statistics during this season shows the highest level of emissions of GHGs and aerosols in 2007. The comparison of the average total emission $(\mathrm{Gg})$ between rice and wheat reveals; burning of rice residue produce more GHGs and aerosols compared to the burning of wheat residue.

\begin{tabular}{rrrrrr}
\hline Year & $\mathrm{CO}_{2}$ & $\mathrm{CO}$ & $\mathrm{NO}_{2}$ & $\mathrm{SO}_{2}$ & $\mathrm{TPM}$ \\
\hline 2002 & 5571.61 & 452.04 & 5.56 & 2.82 & 91.53 \\
2003 & 8083.36 & 655.82 & 8.07 & 4.09 & 132.80 \\
2004 & 6270.23 & 508.72 & 6.26 & 3.17 & 103.01 \\
2005 & 9723.66 & 788.90 & 9.71 & 4.92 & 159.75 \\
2006 & 7179.61 & 582.50 & 7.17 & 3.63 & 117.95 \\
2007 & 13676.58 & 1109.61 & 13.65 & 6.91 & 224.69 \\
2008 & 9953.40 & 807.54 & 9.94 & 5.03 & 163.52 \\
2009 & 7082.67 & 574.63 & 7.07 & 3.58 & 116.36 \\
2010 & 9440.89 & 765.96 & 9.43 & 4.77 & 155.10 \\
2011 & 4102.14 & 332.82 & 4.10 & 2.07 & 67.40 \\
\hline $\mathrm{Avg}$ & 8108.41 & 657.85 & 8.10 & 4.10 & 133.21 \\
\hline
\end{tabular}

Table 6. Total emissions $(\mathrm{Gg})$ of $\mathrm{CO}_{2}, \mathrm{CO}, \mathrm{NO}_{2}, \mathrm{SO}_{2}$ and TPM during rice harvesting season in Punjab

\begin{tabular}{rrrrrr}
\hline Year & $\mathrm{CO}_{2}$ & $\mathrm{CO}$ & $\mathrm{NO}_{2}$ & $\mathrm{SO}_{2}$ & $\mathrm{TPM}$ \\
\hline 2003 & 6512.78 & 590.28 & 1.34 & 1.67 & 54.35 \\
2004 & 5376.51 & 487.30 & 1.10 & 1.38 & 44.86 \\
2005 & 9638.22 & 873.56 & 1.98 & 2.47 & 80.43 \\
2006 & 3941.51 & 357.24 & 0.81 & 1.01 & 32.89 \\
2007 & 10135.23 & 918.60 & 2.08 & 2.60 & 84.57 \\
2008 & 8292.72 & 751.61 & 1.70 & 2.13 & 69.20 \\
2009 & 6931.14 & 628.20 & 1.42 & 1.78 & 57.84 \\
2010 & 3498.86 & 317.12 & 0.72 & 0.90 & 29.20 \\
2011 & 7969.93 & 722.35 & 1.64 & 2.05 & 66.51 \\
2012 & 6671.55 & 604.67 & 1.37 & 1.71 & 55.67 \\
\hline Avg & 6896.85 & 625.09 & 1.42 & 1.77 & 57.55 \\
\hline & & & & &
\end{tabular}

Table 7. Total emissions $(\mathrm{Gg})$ of $\mathrm{CO}_{2}, \mathrm{CO}, \mathrm{NO}_{2}, \mathrm{SO}_{2}$ and TPM during wheat harvesting season in Punjab.
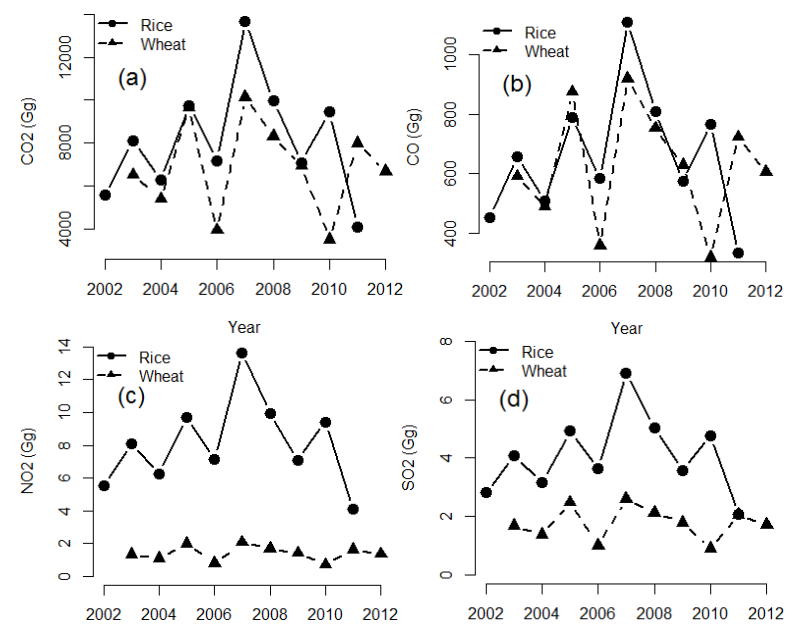

Year

Year

Figure 8. (Continue) 


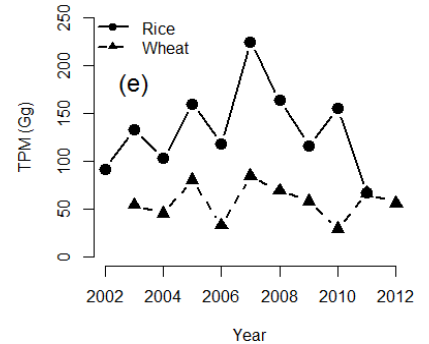

Figure 8. Total emissions of GHG and aerosol during open field combustion of rice (2002-11) and wheat (2003-12) straw in Punjab.

Comparison of the estimated total emissions of GHGs with the respective total emissions reported in the earlier studies (Table 8-9) suggests that they are fairly close to these earlier estimates. However, total estimation of $\mathrm{NO}_{2}$ shows notable differences with the previous concurrent estimates. It is expected that these differences in the total estimations are in fact germinated from the differences in methodological approaches, as well as, the emission factors adopted by the authors to estimate the emission statistics. Conventional approach, which uses residue to product ratio (RPR) to estimate the emission, is based on the quantity of production which augments the total emission as production increases. On the other hand, the approach adopted here is synchronises with vegetation health and leaf area or the biomass content of the plant represented by the average EVI values which, in other words, also represents the production fluctuation over the years. It is noteworthy that comparative statics of estimated total emissions are much accurate in wheat residue burning compared to the burning of rice residue.

\begin{tabular}{lllll}
\hline \multicolumn{5}{l}{ Total emission $(\mathrm{Gg})$} \\
\hline Punjab & Rice & \multicolumn{3}{l}{ Wheat } \\
\hline \multirow{2}{*}{ CO2 } & Estimated $^{\mathrm{a}}$ & Reported $^{\mathrm{b}}$ & Estimated $^{\mathrm{a}}$ & Reported $^{\mathrm{b}}$ \\
\cline { 2 - 5 } $\mathrm{CO}$ & 9953.40 & 12919.72 & 6931.14 & 7105.85 \\
$\mathrm{NOx}(\mathrm{NO} 2)$ & 907.54 & 784.56 & 628.20 & 431.51 \\
$\mathrm{SO} 2$ & 5.03 & 21.23 & 1.42 & 11.73 \\
\hline
\end{tabular}

Table 8. Comparison of the estimated total emission of GHGs to reported total emissions in Punjab (2008-09). ${ }^{\mathrm{a}}$ Estimation for the year 2008 (during rice straw burning) and 2009 (during

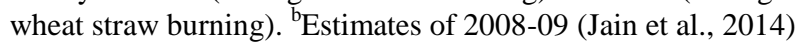

\begin{tabular}{lll}
\hline Punjab & Wheat & \\
\hline \multirow{2}{*}{$\mathrm{CO} 2$} & Estimated $^{\mathrm{a}}$ & Reported $^{\mathrm{b}}$ \\
\cline { 2 - 3 } $\mathrm{CO}$ & 6512.78 & 7548 \\
$\mathrm{NOx}(\mathrm{NO} 2)$ & 590.28 & 118.7 \\
\hline
\end{tabular}

Table 9a. Comparison of the estimated total emissions with reported total emissions of GHGs in 2003 during wheat straw burning. ${ }^{a}$ Estimation for the year 2003 (during wheat straw burning). ${ }^{b}$ Estimates of wheat straw burning 2000 (Sahai et al., 2007).

\begin{tabular}{lll}
\hline Wheat & Estimated $^{\mathrm{c}}$ & Reported $^{\mathrm{d}}$ \\
\hline CO & 192.84 & 113.00 \\
NOx(NO2) & 0.44 & 8.60 \\
\hline
\end{tabular}

Table 9b. Comparison of the estimated total emissions with reported total emissions of GHGs in 2005 during wheat straw burning in Punjab. ${ }^{c}$ Estimation for the year 2005 (during wheat straw burning). ${ }^{\mathrm{d}}$ Estimates of wheat straw burning 2005 (Badarinath et al., 2006).

\section{CONCLUSION}

The analysis, however, demonstrates a detail description of crop mapping, fuel load and emission estimation from fire pixel under rice and wheat cropping system. The approach adopted in this study computes the fuel load in the fire pixel from time averaged EVI. The comparison of fuel load between rice and wheat reveals that quantity of wheat residue used to burn is not as much of rice residue. The comparison of the modelled average fuel load ( $t / h a)$ to that of the reported fuel load in rice field shows fair level of agreement. However, estimated average fuel load for the wheat residue are significantly higher than those of the reported average. The computed emissions of $\mathrm{CO}_{2}$, $\mathrm{CO}, \mathrm{NO}_{2}, \mathrm{SO}_{2}$ and TPM demonstrate strong inter-annual variation between rice and wheat straw burning. The estimated average emission statistics shows that, burning of rice straw spews more GHGs and aerosols than burning of wheat straw. The comparison of the total estimated emissions to the reported emission demonstrates a fair amount of agreement. Hence, the method is also in line with the conventional method of emission inventory. The advantage in this approach is that, it incorporates the spatial variation of emission of a particular species in the fire pixel. The model, however, needs further calibration with respect to the high resolution TM/OLI images to prove its consistency over different data set. Nonetheless, the study portrayed a comprehensive view of the magnitude of emission of these gases and aerosols, representing the background of atmospheric turbidity that varies across time and space.

\section{ACKNOWLEDGEMENTS}

We are thankful to LAADS Web services administered by NASA GSFC for providing required satellite images in absolutely free of charge. First author is thankful to Council of Scientific and Industrial Research (CSIR), Govt. of India for providing fellowship.

\section{REFERENCES}

Andreae, M.O., Merlet, P., 2001. Emission of trace gas and aerosols from biomass burning. Global Biogeochemical Cycles 15, pp. 955-966.

Azzali, S., Menenti, M. 2000. Mapping vegetation-soil-climate complexes in southern Africa using temporal Fourier analysis of NOAA-AVHRR NDVI data. International Journal of Remote Sensing, 21, pp. 973-996.

Badarinath, K.V.S., Kumar Kharol, S., Rani Sharma, A., 2009. Long-range transport of aerosols from agriculture crop residue 
burning in Indo-Gangetic Plains-A study using LIDAR, ground measurements and satellite data. Journal of Atmosphere Solar-Terrestrial Physics, 71, pp. 112-120.

Chang, D., Song, Y., 2009. Estimates of biomass burning emissions in tropical Asia based on satellite-derived data. Atmospheric Chemistry Physics Discussion, 9, pp. 1959919640.

Chen, J., Jönsson, P., Tamura, M., Gu, Z., Matsushita, B., Eklundh, L., 2004. A simple method for reconstructing a highquality NDVI time-series data set based on the Savitzky-Golay filter. Remote Sensing of Environment, 91, pp. 332-344.

Giglio, L., Csiszar, I., Justice, C.O., 2006. Global distribution and seasonality of active fires as observed with the Terra and Aqua Moderate Resolution Imaging Spectroradiometer (MODIS) sensors. Journal of Geophysical Research :Biogeosciences, 111, pp. 1-12.

Gupta, P.K., Sahai, S. 2004. Residue burning in rice - wheat cropping system : Causes and implications, Current Science, 87, pp. 1713-1717.

Gupta, Raj K, Ram K Naresh, Peter R Hobbs, Zheng Jiaguo, and Jagdish K Ladha. 2003. Sustainability of Post-Green Revolution Agriculture: The Rice-Wheat Cropping Systems of the Indo-Gangetic Plains and China In Improving the Productivity and Sustainability of Rice-Wheat Systems: Issues and Impacts. In Improving the Productivity and Sustainability of Rice-Wheat Systems: Issues and Impacts, edited by Jagdish K Ladha, James E Hill, John M Duxbury, Raj K Gupta, and Roland J Buresh, 1st ed., American Society of Agronomy, pp. $1-25$.

Hobbs, P. V, Reid, J.S., Kotchenruther, R.A., Ferek, R.J., Weiss, R., 1997. Direct Radiative Forcing by Smoke from Biomass Burning. Science, 275, pp. 1777-1778.

Hodzic, a., Madronich, S., Bohn, B., Massie, S., Menut, L., Wiedinmyer, C., 2007. Wildfire particulate matter in Europe during summer 2003: meso-scale modeling of smoke emissions, transport and radiative effects. Atmospheric Chemistry Physics Discussion, 7, pp. 4705-4760.

Huete, a., Didan, K., Miura, T., Rodriguez, E.P., Gao, X., Ferreira, L.G., 2002. Overview of the radiometric and biophysical performance of the MODIS vegetation indices. Remote Sensing of Environment, 83, pp. 195-213.

Huete, A., Justice, C., 1999. Modis Vegetation Index Algorithm Theoretical Basis. Department of Environmental Science, University of Virginia, VA, USA, pp. 1-129.

Jain, N., Bhatia, A., Pathak, H., 2014. Emission of Air Pollutants from Crop Residue Burning in India. Aerosol Air Quality Research, 14, pp. 422-430.

Kushwaha, C.P., Singh, K.P., 2005. Crop Productivity and Soil Fertility in a Tropical Dryland Agro-Ecosystem: Impact of Residue and Tillage Management. Experimental Agriculture, 41, pp. 39-50.

Langmann, B., Duncan, B., Textor, C., Trentmann, J., van der Werf, G.R., 2009. Vegetation fire emissions and their impact on air pollution and climate. Atmospheric Environment, 43, pp. 107-116.

Ministry of Agriculture, 2005-07, 2009-11. Districtwise crop production statistics for selected states, crops and given range of years. Directorate of Economics and Statistics, Govt. of India. $\begin{array}{llll}\text { Retrieved on } & 10.02 .2015 & \text { from }\end{array}$ http://apy.dacnet.nic.in/crop_fryr_toyr.aspx.

Ministry of Agriculture, 2012. Agricultural Census data bse. Agricultural Census Division. Govt. of India. Retrieved on 14.02.2015 from http://agcensus.dacnet.nic.in/

Sahai, S., Sharma, C., Singh, D.P., Dixit, C.K., Singh, N., Sharma, P., Singh, K., Bhatt, S., Ghude, S., Gupta, V., Gupta, R.K., Tiwari, M.K., Garg, S.C., Mitra, a. P., Gupta, P.K., 2007. A study for development of emission factors for trace gases and carbonaceous particulate species from in situ burning of wheat straw in agricultural fields in India. Atmospheric Environment, 41, pp. 9173-9186.

Sakamoto, T., Yokozawa, M., Toritani, H., Shibayama, M., Ishitsuka, N., Ohno, H., 2005. A crop phenology detection method using time-series MODIS data. Remote Sensing of Environment, 96, pp. 366-374.

Seiler, W., Crutzen, P., 1980. Estimates of gross and net fluxes of carbon between the biosphere and the atmosphere from biomass burning. Climate Change, 2, pp. 207-247.

Sidhu, B. S., Rupela, O. P., Beri, V., \& Joshi, P. K. 1998. Sustainability implications of burning rice and wheat straw in Punjab. Economic and Political Weekly, 33(39), A163-A168.

Sun, D., Yu, Y., Goldberg, M.D., 2011. Deriving Water Fraction and Flood Maps From MODIS Images Using a Decision Tree Approach. Applied Earth Observation and Remote Sensing, 4, pp. 814-825.

Venkataraman, C., Habib, G., Kadamba, D., Shrivastava, M., Leon, J.-F., Crouzille, B., Boucher, O., Streets, D.G., 2006. Emissions from open biomass burning in India: Integrating the inventory approach with high-resolution Moderate Resolution Imaging Spectroradiometer (MODIS) active-fire and land cover data. Global Biogeochemical Cycles, 20, pp. 1-12.

Yang, S., He, H., Lu, S., Chen, D., Zhu, J., 2008. Quantification of crop residue burning in the field and its influence on ambient air quality in Suqian, China. Atmospheric Environment, 42, pp. 1961-1969.

Zhang, H., Ye, X., Cheng, T., Chen, J., Yang, X., Wang, L., Zhang, R., 2008. A laboratory study of agricultural crop residue combustion in China: Emission factors and emission inventory. Atmospheric Environment, 42, pp. 8432-8441. 